Volume 9, No.1, January - February 2020

International Journal of Advanced Trends in Computer Science and Engineering

Available Online at http://www.warse.org/IJATCSE/static/pdf/file/ijatcse42912020.pdf

https://doi.org/10.30534/ijatcse/2020/42912020

\title{
A Mobile Phone Controllable Smart Irrigation System
}

\author{
Olatunji K. A. ${ }^{1}$, Oguntimilehin A. ${ }^{2}$,Adeyemo O. A. ${ }^{3}$ \\ ${ }^{1}$ Department of Computer Science, Afe Babalola University Ado Ekiti, Ekiti State, Nigeria \\ olatunjikehinde.ok@gmail.com \\ ${ }^{2}$ Department of Computer Science, Afe Babalola University Ado Ekiti, Ekiti State, Nigeria \\ ebenabiodun2@yahoo.com \\ ${ }^{3}$ Department of Computer Science, Afe Babalola University Ado Ekiti, Ekiti State, Nigeria \\ beffitingcrown@gmail.com
}

\begin{abstract}
The increase in technological innovation has made it possible to take full advantage of crop production. The need of a more proficient irrigation system is important for the maximization of crops and the most efficient means of achieving this is with the use of internet of things to control and monitor farms status. Smart irrigation is a very germane component of precision agriculture as it helps farmers to avoid water wastage and improve the quality of crop growth in their fields by reducing evapotranspiration, land runoff and advancing other old usage methods among others. This research aims to use a smart irrigation system to control water distributed to crops. The system does so by connecting the irrigation system and the user's Smartphone through the internet and automating the process of irrigation with computer programming and micro computing. This research was implemented using a microcomputer, internet driver, water pipes and $\mathrm{C}++$ programming language was used with Virtuino for the design of the user interface. The system was tested and the result was $95.5 \%$ efficient.
\end{abstract}

Key words: Agriculture, Internet Driver, Microcomputer, Smart Irrigation, Virtuino.

\section{INTRODUCTION}

Agriculture has a key role to play on the economy growth of the country. Water utilization in the society is on the high rise day by day which may lead to the problem of water scarcity. Currently, farmers are finding it difficult in the agriculture sector and the task of irrigating grassland is becoming quite complicated for the farmers due to lack of steadiness in their work and carelessness because oftentimes they put on the motor and then forget to switch it off leading to water wastage [3].

In [3], Irrigation is a systematic method of artificially providing water to the land or soil that is being cultivated. Conventionally in parched areas with no or little rainfall, there is need for water supply to the fields either by means of canals, hand pumps or tube wells. However, there is limitation to this method because there might be an increase in workload of farm labour leading often to problem such as overirrigation or under-irrigation, and leaching of soil.

According to [2], Modern technological method of implementing irrigation exercise much more efficiently is known as Smart irrigation. It involves the use of sensors, micro-computing and remote communication by farmers to control the application of water to their farm land.

The internet is an interconnection of network enabled devices globally for the purpose of communication, transfer and sharing of data and so on [2]. According to [9], the internet of things (IoT) is the network of devices such as vehicles and home appliances that include electronics, software, actuators and connectivity which allows these equipment to connect, interact and exchange data.

An IoT based irrigation method allows water allocation to crops soil easier, faster and much more proficient by eliminating the need of manual labourers, time wasting decision making and extraction of adequate data from the environment for better distribution of water, fertilizer and nutrients to the soil [1]. Human errors are reduced by replacing 
manual irrigation with automatic valves and systems (e.g. forgetting to turn off a valve after watering the field) and also maximized energy, time, and important resources. The installation and configuration of smart irrigation systems is, in general, fairly straightforward which serves as an advantage in terms of usage by the general public [5].

\section{REVIEW OF RELATED WORKS}

[4] developed a GSM Automated and Smart Irrigation System Using Android. The research was based on finding a way to easily control the temperature and humidity of a greenhouse based on the plants requirement which is difficult to do manually.

The system was implemented by connecting two mobiles using GSM. The GSM module and microcontroller are connected using UART (universal asynchronous receiver / transmitter). When the moisture sensor senses the low moisture content of the soil, it gives a signal to the microcontroller. The microcontroller then gives a signal to the called mobile (which is kept in the auto answering mode). The called mobile activates the buzzer. Therefore when calling mobile calls, that buzzer is heard indicating the valve needs to be open by pressing the button in the called function, the signal is given back to the microcontroller.

The microcontroller gives signal to the valves which causes it to get open. The water is given to the root of the plant drop by drop, and when the moisture content becomes sufficient, the sensor senses this and gives back the signal to the Applications microcontroller and the buzzer becomes off. Then by pressing the button in the calling function again, the valve is made turned off. The power supply needed by the controlling system is $+5 \mathrm{~V}$. The information sharing using only SMS limits the system.

[7] also developed a GSM Based Irrigation System. This irrigation system was designed to use a simple GSM (Global system for mobile communication) device for relaying commands to and receiving information from the system. The interface and communication between user and the designed system is by the means of SMS on GSM network if the user is within the range of $10 \mathrm{~m}$ of designed system.
The system sends the status of power supply through Bluetooth or SMS on GSM network to the user. The system checks the water flow from the pump. If electricity is present but no water supply is available, system sends information to the user through SMS on GSM network. Temperature sensors and humidity sensors which are installed in the field take the measurement of humidity level of soil and environmental temperature and send this information to the user. The user sends data in the form of SMS on GSM network to start or stop the irrigation according to received information.

The system uses an Arduino board which is connected to a GSM modem in which the transmitter of Arduino is connected to the receiver of the GSM modem and the receiver of Arduino is connected to the transmitter of GSM modem. The GSM modem works simply like a mobile phone, when we call on the number of GSM modem; it moves into the auto answering mode and can operate according to the coding which has been done in the microcontroller. The drawback of the system is its lack of autonomy in scheduling water distribution and its geographical challenge of a range not more than $10 \mathrm{~m}$.

[6] developed a Smart Irrigation System for a greenhouse farmers to monitor the soil moisture and temperature of their greenhouse remotely from their android device. The temperature of the soil is detected using temperature sensor and moisture content in soil is detected using soil moisture sensor. Alert message is sent to owner's phone when the sensor values condition is satisfied. The system involves two modes: the automatic and manual mode. The user made decision based on the mode he/she is, if the mode is automatic then automatic system turns ON which makes the system to be ON. And if mode is manual then system turns ON using the input from user application. The User launched the APP and displaying the following option:- (a) Mode. (b) System turns ON/OFF. (C) Control hardware. The user takes corrective action on the particular situation.

The system runs on the Raspberry pi and android operating system. The system's drawback is that it can only work with an android operating systems platform.

\section{SMART IRRIGATION SYSTEM DESIGN}

The system architecture comprises different modules which include: Sensors, Micro-computing chip, 
Internet driver, Applications and Pump. The architecture is presented in Figure 1.

\section{A. Sensor Module}

YL-38 soil moisture sensor is a hygrometer that is usually used to detect the humidity of the soil. So, it is perfect to build an automatic watering system or to monitor the soil moisture of plants. The sensor is set up by two pieces: the electronic board (at the right), and the probe with two pads, that detects the water content (at the left). The sensor has a built-in potentiometer for sensitivity adjustment of the digital output (DO), a power LED and a digital output LED.

\section{B. Micro-computing Chip Module}

Arduino is the micro computing chip employed in this research. An Arduino is an Open Source electronic prototyping platform based on flexible easy to use hardware and software. Arduino boards are able to read inputs - light on a sensor, a finger on a button, or a Twitter message - and turn it into an output - activating a motor, turning on an LED, publishing something online. The board can be told what to do by sending a set of instructions to the microcontroller on the board. To do so, the Arduino programming language (based on Wiring) and the Arduino Software (IDE) based on Processing is used.

\section{Internet Driver Module}

ESP8266 is the internet driver used in this research. The ESP8266 is the name of a micro controller designed by Espressif Systems. The ESP8266 itself is a self-contained WiFi networking solution offering as a bridge from existing micro controller to $\mathrm{WiFi}$ and is also capable of running self-

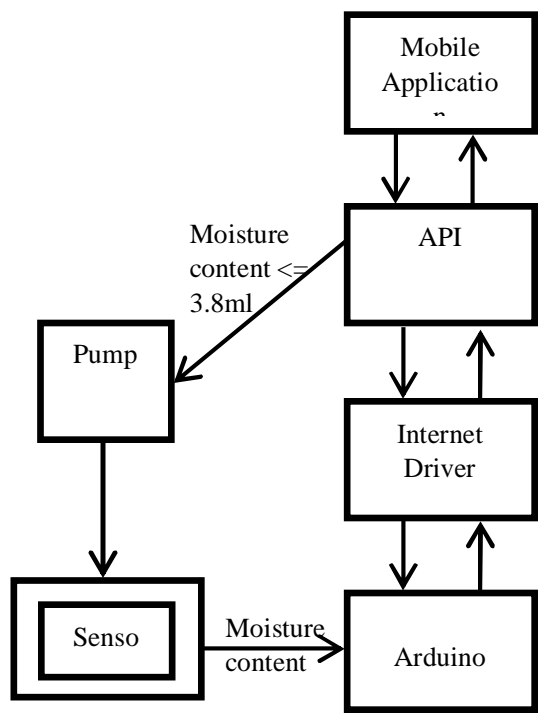

Figure 1: Smart Irrigation System Architecture contained applications. This module comes with a built in USB connector and a rich assortment of pinouts. With a micro USB cable, you can connect NodeMCU devkit to a laptop and flash it without any trouble, just like Arduino. It is also immediately breadboard friendly.

\section{Virtuino Module}

Virtuio is an android application for monitoring sensors or controlling electrical devices via Bluetooth, local Wi-Fi or the internet.

\section{E. Application Module}

For the communication between IoT devices and their servers an application programming interface (API) is essential. An API is a set of subroutine definitions, communication protocols and tools for building software [8].

\section{F. Water Pump Module}

The water pump is the part of the system that delivers water to the soil. The motor drive is used to provide power to the water pump as well as interfacing the pump to the Arduino.

\section{How the System Work?}

The soil moisture sensor which has been placed in the soil reads the soil humidity and sends the readings to the Arduino microcomputer. Arduino then sends the information read to the API through the internet driver using mobile application (Smartphone). If the moisture content is less than $3.8 \mathrm{ml}$ a command is sent back to the pump to initiate or release water to the soil and if otherwise to stop the operation. The farmer also receives information on the whole process of irrigation through the Smartphone.

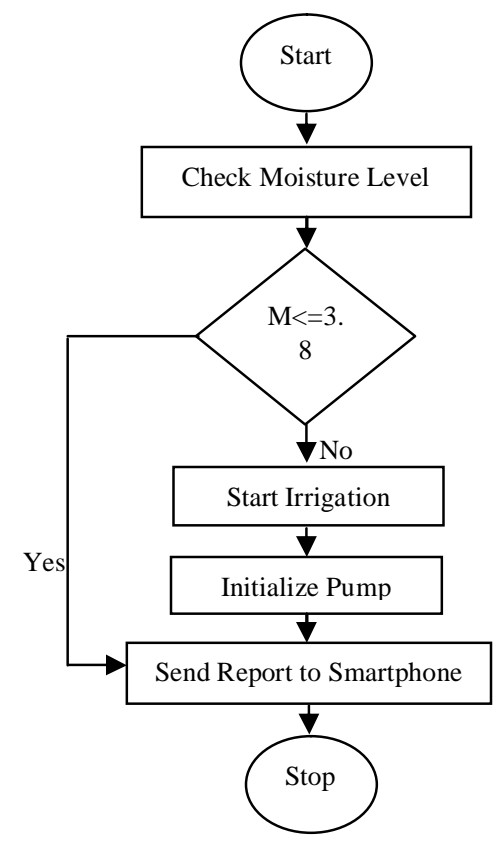

Figure 2: Smart Irrigation System flow Diagram 


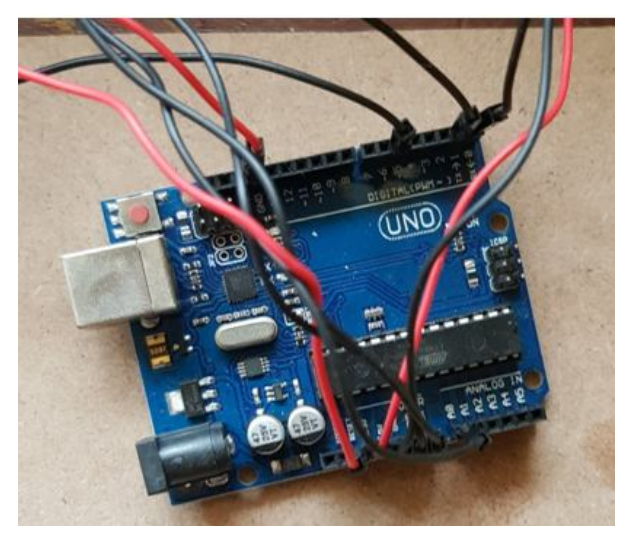

Figure 3: Arduino board with connections

\begin{tabular}{|c|c|}
\hline ESP8266 & Arduino UNO \\
\hline VCC & \multirow{2}{*}{$3.3 \mathrm{~V}$} \\
\hline CH_PD & \\
\hline GND & GND \\
\hline $\mathrm{RX}$ & Pin 4 \\
\hline $\mathrm{TX}$ & Pin 3 \\
\hline
\end{tabular}

Figure 4: Arduino to ESP8266 connection

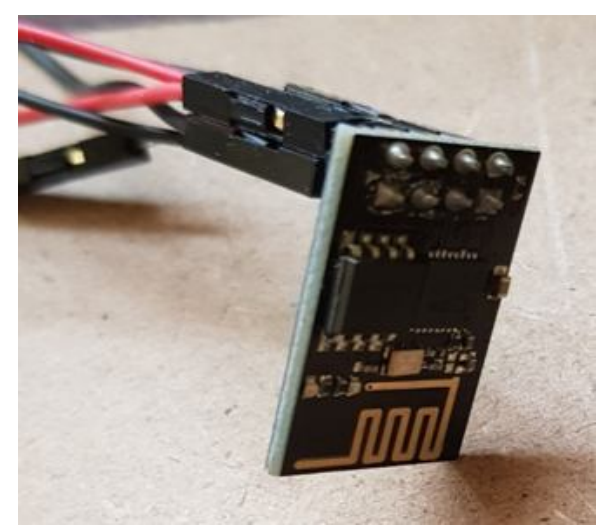

Figure 5: ESP8266

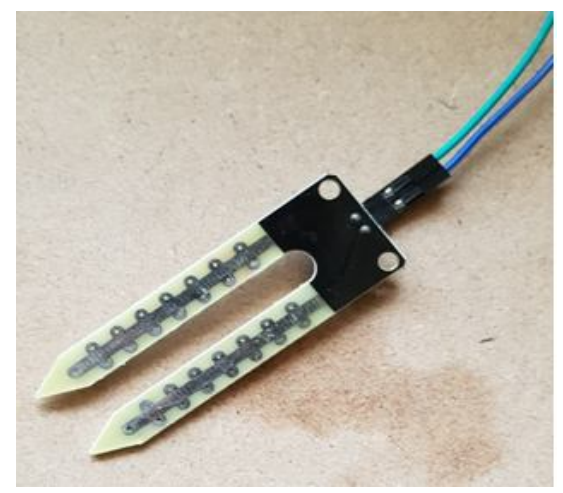

Figure 6: YL-38 Soil Moisture Sensor Module

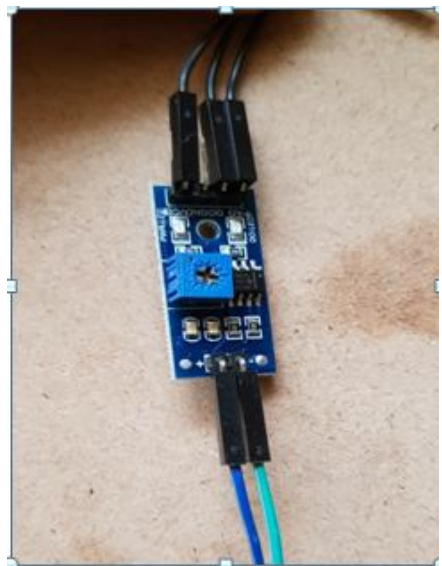

Figure 7: YL- soil moisture Probe

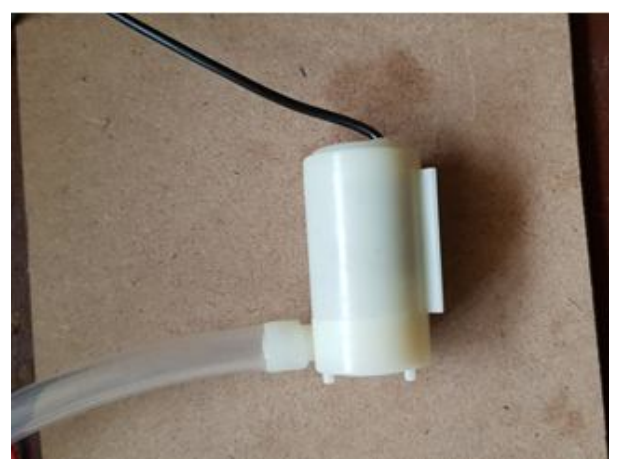

Figure 8: Water Pump

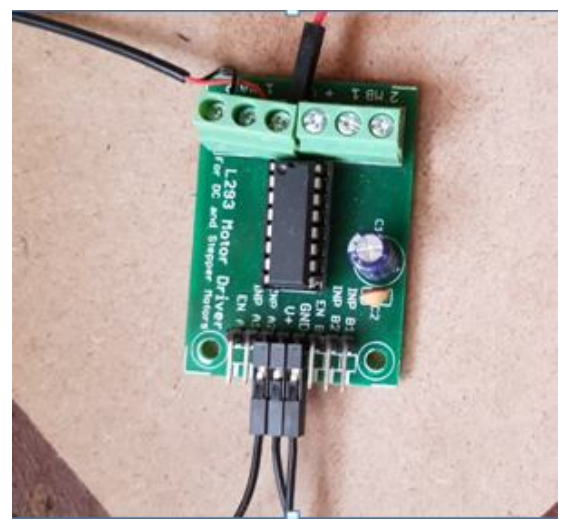

Figure 9: L293d Motor Drive

\section{SYSTEM IMPLEMENTATION}

Figure 2 presents the flow chart diagram of the designed system. Figure 3 to Figure 9 presents the hardware components in the implementation of the designed system. Figure 10 presents the sample test of the designed smart Irrigation System (a case study of a small flower pot).

The implementation of the designed system involves various modules and steps as described as follows: 


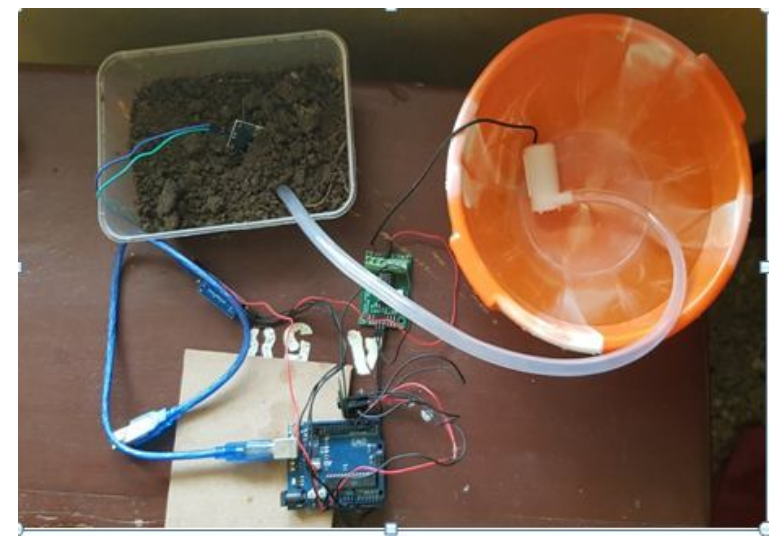

Figure 10: A Sample Test of the Designed Smart Irrigation System.

A. Interfacing of the Arduino board with the Personal Computer

The following steps are taken to interface Arduino board with Personal Computer:

- Install the Arduino USB driver on the PC

- Connect the USB/UART to the Arduino board and the PC

- Open the Arduino IDE

- Go to tools in the IDE and click on board to select your board(Arduino Uno)

\section{B. Connection of the ESP8266 to the Arduino}

The following steps are taken in connecting the ESP8266 to the Arduino:

- Take a two pin connectors and cut them, strip them and connect them to one another in the connector.

- Connect the two headed pin connector newly created to the VCC and CH_PD on the ESP8266 the other one headed side to the $3.3 \mathrm{~V}$ pin on the Arduino board

- Connect the GND pin on the ESP8266 to the GND pin on the Arduino

- Connect the RX pin on the ESP8266 to the pin4 on the Arduino

- Connect the TX pin on the ESP8266 to the pin3 on the Arduino

\section{Connection of Soil Sensor}

These are the steps taken to connect the soil sensor.

- Connect two pin connectors to the YL-38 soil moisture sensor module and a YL- soil moisture Probe. (NOTE: Wire polarity not important).
- Connect the A0 pin on the soil sensor and connect to A0 on Arduino.

- Connect the GND pin on the soil sensor and connect to GND on Arduino.

- Connect the VCC pin on the soil sensor and connect to $5 \mathrm{~V}$ on Arduino.

D. Connection of Water Pump to the system The following steps are taken to connect the water pump to the system:

- Connect the negative wire on the pump to the MA1 slot on the motor drive

- Connect the positive wire on the pump to the MA2 slot on the motor drive

- Connect the $-\mathrm{V}$ pin on the motor to the GND pin on the Arduino

- Connect the Enable A pin on the motor to the $5 \mathrm{~V}$ pin on the Arduino

\section{E. Connection of API}

For the communication between IoT devices and their servers an application programming interface (API) is essential. An API is a set of subroutine definitions, communication protocols and tools for building software. For this project 'Thingspeak API' was used.

Setting up a Thingspeak channel

- Sign up to the thingspeak website

- Fill new channels name

- Create fields for the recorded data, in this case two

- Go to the API key option

- Generate read and write key

- Go to channels field and set result parameters to 5

\section{CONCLUSION}

In conclusion the main purpose of this research is to develop a smart irrigation system with the functionalities to detect the soil moisture level, apply water to the soil if the moisture level is below a specified standard and interact with the user of the system through Smartphone. The implementation of the system involves a combination of hardware and software including: a micro-computing chip, a soil sensor, an internet driver, a water pump and a motor driver. The system was tested using a flower pot and the result was $95.5 \%$ efficient. 
The Smart Irrigation System is meant to meet the need of a farmer with a small scaled plantation and can also be further extended to be useful for a large scaled agricultural plantation farmer.

\section{REFERENCES}

1. C. N. Lakshmiprasad, R. Aashish, and M. J. Syed "IoT Based Smart Irrigation System," Journal of Electrical and Electronics Engineering (IOSR-JEEE), e-ISSN: 2278-1676, p-ISSN: 2320-3331, Volume 9, Issue 6, ver 1, pp34-40, Nov-Dec 2014, www.iosrjournals.org

2. G. R. Kumar, T. V. Gopal, V. Sridhar, G. Nagendra, "Smart Irrigation System," International Journal of Pure and Applied mathematics, Vol 119 Issue15, pp1155-1168.

3. H. N. Kamalaskar, and Dr. P. H. Zope, "Survey of Smart Irrigation System," International Journal of Engineering Sciences and Research Technology, ISSN 2277-9655, vol3 issue6: pp 224-228, June 2014.

4. J. Ravichandran, "Based on GSM Automated and Smart Irrigation System Using Android," International Journal of Trend in Scientific Research and Development (IJTSRD), International Open Access Journal, ISSN No: 2456 - 6470 volume 3, Nov-Dec 2018 https://doi.org/10.31142/ijtsrd 18944

5. K. Bhagyashree and Prof. J. G. Rana, "Smart Irrigation System Using Raspberry PI," International Research Journal of Engineering and Technology (IRJET), e-ISSN: 2395 -0056, Volume: 03 Issue: 05, August 2016

6. L. A. Vishal, P. B. Arti, A. Tejaswini, K. Amit, and Prof. P. SaiPrasad, "Smart Irrigation System," International Journal of Scientific Research in Science and Technology (IJSRST), Volume 2 Issue 5, Print ISSN: 2395-6011, pp343-345, September - October 2016.

7. P. Lahande, and Dr. B. Mathpathi (2018), "IoT Based Smart Irrigation System," International Journal of Trend in Scientific Research and Development (IJTSRD), ISSN: 2456-6470, Vol 2 Issue 5, pp 359-362. https://doi.org/10.31142/ijtsrd15827

8. Wikipedia, Application Programming Interface. [Retrieved online at https://en.wikipedia.org/wiki/Application_progra mming_interface February, 2019]
9. Wikipedia, Internet of Things. [Retrieved online at https://en.wikipedia.org/wiki/Internet_of_things, November, 2018] 